\title{
Montanhismo: um relato de experiência da interdisciplinaridade entre educação física e geografia
}

\author{
Mountaineering: an experience report of interdisciplinarity between \\ physical education and geography \\ Marcelo Faria Porretti, ${ }^{1,2}$, Fernando Amaro Pessoa ${ }^{2}$, Monique Ribeiro de Assis ${ }^{1}$ \\ ${ }^{1}$ Universidade Estadual do Rio de Janeiro (UERJ), Rio de Janeiro/RJ, Brasil \\ ${ }^{2}$ Centro Federal de Educação Tecnológica (CEFET), Petrópolis/RJ, Brasil
}

\section{HISTÓRICO DO ARTIGO}

Recebido: 14 novembro 2019 Revisado: 01 abril 2020

Aprovado: 08 abril 2020

\section{PALAVRAS-CHAVE:}

Meio Ambiente; Montanhismo; Ensino Médio.

\section{KEYWORDS:}

Environment; Mountaineering; Education secondary.

\section{RESUMO}

INTRODUÇÃO: Ao debater as questões ambientais, apresentamos o trabalho interdisciplinar de educação física e geografia no montanhismo.

OBJETIVO: Apresentar a experiência de uma proposta pedagógica interdisciplinar na prática corporal de aventura de montanhismo no CEFET/RJ, campus Petrópolis.

MÉTODOS: Pesquisa de caráter qualitativa descritiva, onde debatemos as atividades interdisciplinares realizadas no projeto de extensão Expedições do CEFET/RJ, campus Petrópolis, com a participação de alunos do Ensino Médio e graduandos em Turismo. Os dados foram obtidos a partir de relatórios individuais, os quais foram analisados, ordenados e classificados de acordo com Gomes (2002).

RESULTADOS: São relatadas, avaliadas e discutidas sete atividades desenvolvidas no ano de 2018 - trilhas e caminhadas no Morro Meu Castelo por duas vezes, Pedra do Quitandinha, Travessia Cobiçado-Ventania, Travessia Uricanal, Travessia Petrópolis-Teresópolis e Caminho do Ouro; onde foram arrolados os temas, na educação física: frequência cardiorrespiratória, percepção de esforço, recreação e lazer, turismo de aventura, compreensão dos limites individuais, hidratação, monitoramento da frequência cardíaca, escala modificada de Borg, alimentação, história do montanhismo, combate ao sedentarismo e práticas corporais de aventura; na geografia: ecossistemas, urbanização, paisagem antropizada, geociências, relevo, bacias hidrográficas, patrimônio natural e contexto histórico; em ambas as disciplinas: saúde, educação ambiental, justiça ambiental, interpretação ambiental, sustentabilidade, preservação e conservação da natureza. O imaginário, os riscos, a prática regular de atividade física e consciência ambiental foram os resultados mais apontados. CONCLUSÃO: A educação física escolar resignificou conteúdos e processos de ensino-aprendizagem de forma interdisciplinar a partir de aspectos que procuraram influenciar os participantes em termos pessoais, escolares, físicos e também emocionais, na busca da formação de um cidadão mais consciente e participativo na sociedade.

\section{ABSTRACT}

BACKGROUND: When discussing environmental issues, we present the interdisciplinary work of Physical Education and Geography in mountaineering.

OBJECTIVE: To present the experience of an interdisciplinary pedagogical proposal in the corporal practice of mountaineering of adventure at CEFET/RJ, campus Petrópolis.

METHODS: This is a descriptive qualitative research, in which we discuss the interdisciplinary activities carried out in the extension project Expeditions of CEFET/RJ at the campus Petrópolis, with the participation of high school students and undergraduate students in Tourism. The data were obtained from individual reports, which were analyzed, ordered and classified according to Gomes (2002).

RESULTS: Seven activities developed in 2018 are reported, evaluated and discussed - trails and hikes in Morro Meu Castelo - twice, Pedra do Quitandinha, Travessia Cobiçado-Ventania, Travessia Uricanal, Travessia Petrópolis-Teresópolis and Caminho do Ouro; being listed the following themes, in physical education: cardiorespiratory frequency, perception of effort, recreation and leisure, adventure tourism, understanding of individual limits, hydration, heart rate monitoring, modified Borg scale, eating habits, history of mountaineering, combating physical inactivity and adventure bodily practices; in geography: ecosystems, urbanization, anthropized landscape, geosciences, terrains, river basins, natural heritage and historical context; in both disciplines: health, environmental education, environmental justice, environmental interpretation, sustainability, preservation and conservation of nature. The imaginary, the risks, the regular practice of physical activity and environmental awareness were the most highlighted results.

CONCLUSION: School physical education reframed contents and teaching-learning processes in an interdisciplinary way from aspects that sought to influence participants in personal, educational, physical and also emotional terms, in the search for the formation of a more conscious and participative citizen in society. 


\section{INTRODUÇÃO}

A busca pela natureza, como descreve Bruhns (2009), é aventureira, e no gesto aventureiro se trabalha o imaginário, envolve-se o risco, no qual se brinca de ser herói, de forma lúdica essa associação procura desenvolver nos indivíduos um estilo ecológico, consciente de seus direitos e deveres, favorável a uma imersão de construções de valores e autodescobertas que as práticas corporais de aventura podem proporcionar.

Ao debater as questões ambientais, Bruhns (2009) nos mostra que a natureza não deve ser vista como algo intocado, o que é abordado, inclusive, como um mito moderno na perspectiva de Diegues (1996), sendo amplas as relações dialéticas estabelecidas entre sociedade e natureza. A imersão em ambientes naturais, por muitas vezes, é apresentada como uma fuga das relações sociais consumistas e capitalistas do mundo moderno. Porém, como descreve a autora anteriormente citada, é necessária uma multiplicidade de contatos com a natureza para entender que o desafio contemporâneo requer a busca de reinvenções, perpassando o meio político e novos meios de convívios e valores, instaurando-se uma resignificação da própria vida, o que envolve o ato de exercitar-se.

Atrelando-se as atividades de aventura ao lazer, nos é relatado por Piovani (2013) que este contato com o meio natural pode significar uma busca pelo tempo livre de forma mais humana, ajudando no desenvolvimento de indivíduos mais autônomos frente aos riscos que estas atividades proporcionam.

Carvalho (2008) descreve que a escola é um local onde a educação ambiental deve ser debatida e incluída de forma a valorizar as questões socioambientais. Porretti (2011), ao pesquisar sobre a inserção do tema transversal meio ambiente nas aulas de educação física escolar no município de Petrópolis, verificou que somente oito (8) dos sessenta e quatro (64) docentes da rede municipal de ensino abordavam o tema, porém ao realizar uma ida a campo com entrevistas detectou poucas ações que realmente ocorriam. Assim, cabe destacar os debates e as ações mais efetivas, das atividades da disciplina escolar de educação física no município de Petrópolis com as questões ambientais, visto todo contexto geográfico ao qual está inserido o território deste município da Região Serrana do Estado do Rio de Janeiro.

Neste contexto territorial, iniciou-se em 2015 no campus Petrópolis do CEFET/RJ o Curso Técnico em Telecomunicações Integrado ao Ensino Médio e com ele desafios presentes em todo o processo educacional. A Educação Física, que no âmbito escolar é quase sempre vista como uma aula feita para os discentes extravasarem suas energias, fazendo-os sair da sala de aula, engajou-se no processo educacional da instituição, o que envolve muitos desafios, dentre eles a falta de quadra e espaço apropriado para prática de atividades físicas, fato que não é novidade nenhuma para vários professores de educação física. Porém, estávamos num município cercado de questões relativas à natureza.

A partir da motivação de trabalhar com questões relacionadas ao meio ambiente ${ }^{1}$, foi construída uma parceria entre

${ }^{1}$ Graduado desde 1998 o primeiro autor vem realizando atividades relacionadas ao meio ambiente e caminhada em trilhas nas aulas de Educação Física, temática ao meio a miente e caminhada em trilhas nas aulas de Educação Fisica, temática desenvolvida centes de Educação Fisica das escolas municipais de Petrópolis sobre uma reflexão curricular para uma Sociedade Sustentável", no ano de 2011. algumas disciplinas escolares tendo como base a prática das atividades físicas ao ar livre, permeado pela interdisciplinaridade, surgindo uma parceria de aventuras didático-pedagógicas entre as disciplinas de educação física e geografia.

Na busca desta vertente foi criado o projeto de extensão "Expedições do CEFET/RJ - campus Petrópolis", que envolve professores, alunos e funcionários técnico-administrativos da instituição, além de participantes externos. Este projeto de extensão, em andamento desde 2015, possui como objetivo desenvolver atividades que estejam de acordo com o paradigma ecológico atual, desenvolvidas em sua maioria em trilhas inseridas nos limites do Parque Nacional da Serra dos Órgãos (PARNASO), perpassando por aspectos como: preservação, práticas alternativas de lazer, contraponto a vida moderna e busca de melhor qualidade de vida a partir da interação com a natureza (Dias, 2008).

Com isso, destaca-se a atividade de campo como uma prática essencial e enriquecedora, desenvolvida nesse projeto de extensão através de expedições mensais de cunho pedagógico associadas aos conteúdos ministrados em diversas disciplinas, trabalhados de maneira integrada e devidamente embasados teoricamente a partir de textos que são discutidos em encontros semanais. O trabalho de campo como ferramenta de ensino/aprendizagem funciona como ilustração, exemplificação, de forma empírica do que é apresentado no ambiente de estudo. Nesse contexto, nosso enfoque aqui será a educação física escolar e suas parcerias interdisciplinares, com as atividades embasadas no caráter multifatorial da saúde, onde Farinatti e Ferreira (2006) descrevem que a saúde dos indivíduos decorre de diversos aspectos, dentre eles o socioeconômico, o ambiental, o biológico e o profissional.

O CEFET/RJ - Campus Petrópolis pertence a um município que se destaca na questão ambiental, sobretudo em relação às florestas e a áreas protegidas, quando comparado com municípios vizinhos, protegendo áreas remanescentes da Mata Atlântica como, por exemplo, o PARNASO, um dos mais antigos Parques criados no Brasil, e a Área de Proteção Ambiental de Petrópolis, a primeira criada em nosso país (Castro Jr. et al., 2009). Daí o destaque e potencial para a realização de atividades ao ar livre.

Justificamos nosso trabalho com as características ambientais do município de Petrópolis, que acabam por motivar as práticas de montanhismo, uma vez que as caminhadas pelas trilhas de Petrópolis são conhecidas internacionalmente. Em conversa com os alunos, nos foi relatado que alguns eram adeptos desta prática, outros desconheciam lugares e trilhas até mesmo próximo de suas casas, um terceiro grupo tinha vontade de realizar as atividades, porém não tinham companhia e/ou receio de familiares para tal prática.

A literatura aponta algumas diferenciações e aproximações entre os termos trekking, montanhismo e escalada. Mas para fim do nosso estudo iremos utilizar Pereira (2007, p. 40), que descreve o montanhismo como "a exploração de montanhas, caminhando ou escalando, em montanhas nevadas ou não". Sendo assim, iremos relatar as ações desenvolvidas no presente trabalho como práticas de montanhismo.

Desta forma nosso objetivo no presente trabalho é apresentar a experiência de uma proposta pedagógica interdisciplinar na prática corporal de aventura de montanhismo no CEFET/RJ campus Petrópolis. 


\section{MÉTODOS}

Pesquisa de caráter qualitativo onde descrevemos um relato de experiência da nossa imersão no campo apoiados em Thomas, Nelson e Silverman (2012), Alves-mazzotti e Gewandsznajder (2002), Flick (2009), Gil (1995) e Cruz Neto (2002), onde, selecionar e investigar nossa ida a campo facilita a aproximação do conhecer e estudar, gerando novos conhecimentos para aplicabilidade futura. Pois, discutir a experiência da ida a campo não é restrita a uma única ciência, entendemos que a relação e percepção dos pesquisadores com os sujeitos pesquisados são de extrema importância.

Aulas teóricas foram utilizadas nas disciplinas de Educação Física e Geografia para a promoção de debates sobre as relações entre sociedade, natureza e saúde. A partir daí, as trilhas são planejadas em reuniões do projeto de extensão, onde se definiam que turmas participariam de cada atividade, no caso, os alunos do Ensino Médio e graduandos em Turismo do CEFET/RJ, campus Petrópolis.

Desta forma, levamos ao debate pedagógico e interdisciplinar a prática do montanhismo, realizando caminhadas por trilhas no município de Petrópolis e seu entorno, correlacionando nas aulas de educação física o monitoramento de frequência cardíaca, nível de cansaço pela escala de Borg², exercícios aeróbios, combate ao sedentarismo, companheirismo, solidariedade; em geografia: relevos, paisagens, paisagens antropizadas, geodiversidade, biodiversidade, sociodiversidade, dentre outros temas. Por fim, de forma conjunta as duas disciplinas desenvolveram questões relacionadas à educação ambiental, justiça ambiental, preservação e conservação da natureza.

Coletamos os dados desta parceria interdisciplinar através de relatórios das atividades, analisando segundo Gomes (2002) com a ordenação dos dados: nossas idas a campo durante o ano de 2018; classificando os dados: com as propostas interdisciplinares; análise final: estabelecendo articulações entre os dados e os referenciais teóricos.

Em conformidade com a Resolução CNS N. 466/12 que regulamenta a pesquisa em seres humanos no Brasil foram repeitados todos os aspectos éticos e a pesquisa encontra-se aprovada sob Parecer $\mathrm{N}^{\circ}$. 2.531.392.

\section{RESULTADOS}

Para descrever com maior ênfase as práticas corporais de aventuras didáticas desenvolvidas pela parceira das disciplinas educação física e geografia, iremos relatar as experiências das atividades desenvolvidas (Quadro 1) no ano de 2018 a partir do projeto de extensão "Expedições do CEFET/RJ campus Petrópolis". Nesse ano ocorreram sete atividades, algumas dentro do horário escolar das disciplinas e outras em horários alternativos com participação opcional dos alunos, conforme descrito a seguir. É importante expor que devido às condições climáticas algumas atividades foram desmarcadas e outras não foram realocadas por organização do calendário acadêmico.

1-Trilha para o morro Meu Castelo (Castelinho, Figura 2) - abril/2018 atividade foi voltada para as turmas de primeiro ano do Curso Técnico

BORG, G. Physical Performance and Perceived Exertion. Studia Psychologica Et Pedagogica,1962. p. 1-32. em Telecomunicações Integrado ao Ensino Médio. Esta é uma aula tradicional da parceria didática, pois sua proximidade com a escola favorece o desenvolvimento pedagógico da prática corporal de aventura do montanhismo, sendo uma trilha de fácil acesso, extensão aproximada de $2,6 \mathrm{Km}$, curta duração (aproximadamente 40 minutos), sem dificuldades técnicas, com ganho de elevação de cerca de 200 metros e altitude máxima de 1.245 metros (GARCIA NETO, 2008).

Antes de iniciar a caminhada foi realizado um aquecimento, alongamento e destacado pontos relevantes na trilha, como bifurcações, por exemplo. Foi medida a frequência cardíaca com auxilio de um relógio de pulso, onde os alunos já haviam sido orientados na escola de como realizar a marcação (apalpando a veia jugular com os dedos indicadores e médio). Processo que foi repetido mais duas vezes durante a caminhada a fim de avaliarem sua condição cardiorrespiratória e entenderem os limites individuais de cada um.

Quadro 1. Resumo das atividades interdisciplinares realizadas no ano de 2018.

\begin{tabular}{|c|c|c|c|}
\hline Atividades/Trilhas & $\begin{array}{l}\text { Mês } \\
\text { (2018) }\end{array}$ & $\begin{array}{l}\text { Propostas } \\
\text { trabalhadas }\end{array}$ & $\begin{array}{c}\text { Temas que } \\
\text { perpassaram todas } \\
\text { as atividades }\end{array}$ \\
\hline $\begin{array}{l}\text { 1- Morro Meu } \\
\text { Castelo (Castelinho) }\end{array}$ & Abril & $\begin{array}{l}\text { Frequência cardiorres- } \\
\text { piratória; ecossistemas; } \\
\text { bacias hidrográficas e } \\
\text { urbanização. }\end{array}$ & \multirow{4}{*}{$\begin{array}{c}\text { Educação } \\
\text { ambiental; } \\
\text { Justiça ambiental; }\end{array}$} \\
\hline $\begin{array}{l}\text { 2- Pedra do } \\
\text { Quitandinha }\end{array}$ & Maio & $\begin{array}{l}\text { Percepção de esforço, } \\
\text { aspectos históricos e } \\
\text { paisagem antropizada. }\end{array}$ & \\
\hline $\begin{array}{l}\text { 3- Morro Meu } \\
\text { Castelo (Castelinho)/ } \\
\text { Noturna }\end{array}$ & Junho & $\begin{array}{l}\text { Recreação e lazer, } \\
\text { turismo de aventura e } \\
\text { geociências. }\end{array}$ & \\
\hline $\begin{array}{l}\text { 4- Travessia } \\
\text { Cobiçado-Ventania }\end{array}$ & Junho & $\begin{array}{c}\text { Compreensão dos limites } \\
\text { individuais, hidratação } \\
\text { e relevo. }\end{array}$ & \\
\hline $\begin{array}{l}\text { 5- Travessia } \\
\text { Uricanal }\end{array}$ & Julho & $\begin{array}{l}\text { Monitoramento da } \\
\text { frequência cardíaca, } \\
\text { ecossistemas e bacias } \\
\text { hidrográficas. }\end{array}$ & $\begin{array}{l}\text { Preservação e } \\
\text { conservação da } \\
\text { natureza; }\end{array}$ \\
\hline $\begin{array}{l}\text { 6- Travessia } \\
\text { Petrópolis-Tere- } \\
\text { sópolis }\end{array}$ & Julho & $\begin{array}{l}\text { Escala modificada } \\
\text { de Borg, frequência } \\
\text { cardíaca, alimentação, } \\
\text { patrimônio natural, } \\
\text { ecossistemas, história do } \\
\text { montanhismo. }\end{array}$ & \multirow[t]{2}{*}{$\begin{array}{l}\text { Práticas corporais de } \\
\text { aventura; }\end{array}$} \\
\hline $\begin{array}{l}\text { 7- Caminho do } \\
\text { Ouro }\end{array}$ & Novembro & $\begin{array}{l}\text { Combate ao sedentaris- } \\
\text { mo, relevo e contexto } \\
\text { histórico. }\end{array}$ & \\
\hline
\end{tabular}

Ao chegar no cume do morro Meu Castelo, os professores dialogaram com os alunos os aspectos relevantes da triIha, sobre o ecossistema, a geologia/geomorfologia local além de destacar o cume como um importante divisor de águas no contexto hidrográfico regional do estado do Rio de janeiro: bacias da Baía de Guanabara e do rio Paraíba do Sul. Aspectos como a paisagem natural modificada pelo homem puderam ser observadas, principalmente na Região Metropolitana do Rio de Janeiro desenvolvida no entorno da Baía de Guanabara, além de um pequeno debate sobre pichações existentes nas rochas do topo da trilha. Assim, identificamos as discussões sobre educação ambiental, apresentadas por Carvalho (2008), que aponta a escola como um local chave para serem trabaIhadas as questões socioambientais.

2 - Trilha para a Pedra do Quitandinha - maio/2018: aberta para alunos do segundo, terceiro e quarto ano do Ensino Médio. Com baixa 
dificuldade, fácil orientação, duração aproximada de 1 hora, distância percorrida de $2.8 \mathrm{~km}$ e uma altitude máxima de 1.100 metros (GARCIA NETO, 2008). Foi realizado aquecimento prévio com alongamento e medido pelos próprios colegas o nível do cansaço pela Escala Modificada de Borg (CAVALLAZZI et al., 2005). No topo foi possível contemplar o Palácio e o Lago Quitandinha sob outras perspectivas, estimulando uma abordagem geográfica sobre interpretação da paisagem abordando os aspectos ambientais do local, como ocupações em áreas de risco e movimentos de massa.

3 - Trilha noturna para o morro Meu Castelo (Castelinho) - junho/2018: realizada com os alunos do terceiro e quarto ano do Ensino Médio Integrado acompanhado dos alunos do curso de Bacharelado em Turismo. Uma trilha noturna apresenta características que vão além do uso das lanternas. Os sons são mais nítidos, o receio de andar sozinho no escuro faz com que queriam sempre companhia de colegas. Mesmo a noite é interessante observar a Baía de Guanabara contornada por luzes que expressam a principal malha urbana do estado do Rio de Janeiro, local privilegiado para a discussão de aspectos importantes das geociências e do turismo de aventura, com expressiva atividade turística e potencial didático.

As próximas atividades apresentadas representam trechos do projeto de trilha de longa duração "Caminhos da Serra do Mar" (Figura 1), que percorre o núcleo do Parque Nacional da Serra dos Órgãos, abarcando diversos municípios e unidades de conservação do Mosaico da Mata Atlântica Central Fluminense. De acordo com o ICMBio/PARNASO (2016), o principal objetivo desta trilha de longo curso é favorecer a conservação ambiental a partir do uso público ordenado, apresentando este território como prioritário para as práticas de montanhismo, caminhadas, contemplação, recreação e lazer, o que pôde ser experimentado pelas atividades realizadas nesta parceria interdisciplinar.

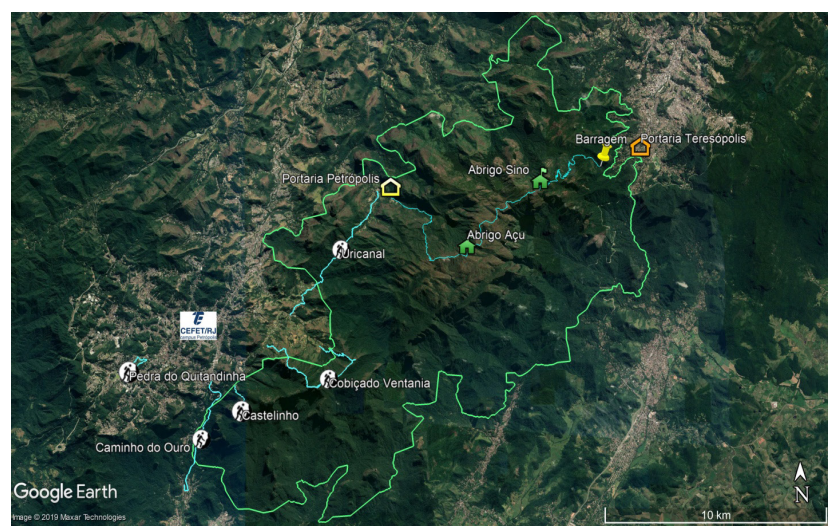

Figura 1. Distribuição espacial das trilhas realizadas e do CEFET/RJ campus Petrópolis (arquivo pessoal do autor).

No mapa (Figura 1), as linhas azuis representam os percursos das trilhas e a linha verde o limite territorial do Parque Nacional da Serra dos Órgãos. As trilhas da Pedra do Quitandinha e do Castelinho são mais curtas, no modelo bate-volta e juntas somam cerca de $10 \mathrm{~km}$ percorridos. Já as demais são travessias, em que a caminhada começa em um local e termina em outro. Os trechos do Caminho do Ouro, Travessia Cobiçado-Ventania, Travessia Uricanal e Travessia Petrópolis-Teresópolis representam o projeto de trilha de longa duração "Caminhos da Serra do Mar", totalizando cerca de $70 \mathrm{~km}$ de extensão.
4 - Trilha da Travessia Cobiçado - Ventania, situada no bairro Caxambu - junho/2018: nesta atividade alguns alunos optaram por não participar, tendo em vista o grau de exigências apresentados. Foi uma atividade acompanhada de perto pelos docentes, apresentando-se como uma preparação para uma jornada sonhada por muitos alunos: a travessia Petrópolis-Teresópolis, mas, que somente um grupo reduzido poderia participar.

Foram 8 horas de caminhada, classificada como de dificuldade média, necessitando cuidados por existência de alguns trechos de passagens expostas, terreno escorregadio, orientação da trilha, distância aproximada de $12,4 \mathrm{~km}$, e altitude máxima de 1.740 metros (GARCIA NETO, 2008).

Antes de iniciarmos, mais uma vez foi realizado alongamento, aferição de batimentos cardíacos e a Escala Modificada de Borg, fatores estes que iríamos considerar para outra travessia, como dito anteriormente. A trilha começa com uma subida íngreme e desnível aproximado de 700 metros, exigindo um esforço a mais por parte dos nossos alunos aventureiros, mas esse esforço acaba com a chegada ao cume do Cobiçado. Deste trecho em diante caminha-se na crista da montanha, com alguns aclives e declives chega-se ao Pico dos Vândalos, trecho mais alto desta travessia. Mais algumas descidas e subidas para se chegar a outra extremidade da trilha, o cume Ventania, onde começamos a descida para finalizar a travessia.

Esta atividade envolveu toda a logística de um dia inteiro de caminhada, preocupações com alimentação, água, proteção solar, exposição a riscos maiores, risco de animais peçonhentos, ficando claro que o desafio aqui ia além das caminhadas anteriores.

5 - Trilha da Travessia Uricanal - julho/2018: aberta para todos os alunos do Ensino Médio, essa trilha liga o bairro do Caxambu ao bairro do Bonfim, importantes centros de produção agrícola do município de Petrópolis. Nesta atividade somente realizamos um aquecimento inicial, cada aluno poderia ficar a vontade para monitorar sua frequência cardíaca. Esta trilha destaca-se por ocorrer em um vale suspenso, margeando um rio e com presença de ecossistemas florestais da Mata Atlântica em estágio avançado de sucessão ecológica, inclusive com a presença de algumas espécies ameaçadas de extinção.

6 - Trilha da Travessia Petrópolis-Teresópolis - julho/2018: realizada em três dias de caminhada na montanha, essa atividade representava o grande desafio do projeto até então. Além de ser considerada uma atividade clássica do montanhismo nacional, a Travessia Petrópolis-Teresópolis também é apontada por muitos como uma das mais bonitas do Brasil. A trilha fica totalmente dentro do PARNASO, sendo assim protegida pelo Instituto Chico Mendes de Conservação da Biodiversidade (ICMBio), que controla o uso público do parque impondo alguns limites para a visitação, como por exemplo um limite diário de 100 pessoas na parte alta do parque (nos trechos que comportam abrigos da Travessia). Além disso, o ICMBio também desenvolve ações relacionadas a educação ambiental possibilitando o uso sustentável do território com práticas de lazer, estudos e pesquisas. O parque é um dos mais visitados e pesquisados do país (ICMBio, 2019).

Como relatado anteriormente, para esta atividade os alunos passaram por um processo de amadurecimento em participações anteriores, os qualificando para participar. Avaliamos qualitativamente as condições físicas e psicossociais (observamos solidariedade, companheirismo, liderança no grupo, dentre outros) no decorrer de um semestre letivo. Foi necessária uma logística especial, pois a travessia é considerada com um alto grau de dificuldade (GARCIA NETO, 2008; ICMBIO/PARNASO, 2019), exigindo esforço físico, passagens por trechos técnicos, escaladas, alimentação para três dias de atividades, 
limitações de pontos de água e abastecimentos, enfim, uma aventura completa para os alunos durante os $30 \mathrm{~km}$ de extensão com mais de 2.000 metros de ganho de elevação.

Recebemos o reforço de mais três docentes da instituição, sendo selecionados três alunos de graduação (Curso de Bacharelado em Turismo) e cinco do Ensino Médio (Curso Técnico em Telecomunicações integrado ao Ensino Médio), além de um ex-aluno e um convidado (Figura 2). Foram estabelecidos critérios rigorosos, uma vez que alguns alunos não tinham atingido a maioridade legal, o que gerou necessidade de documentação e autorização dos responsáveis autenticada em cartório, mais o termo de conhecimento de risco e normas exigido pela unidade de conservação. Também foi realizada uma reunião prévia para orientar pais e alunos selecionados, informando-os sobre os cuidados e riscos que envolvem esta atividade de aventura, como por exemplo: alimentação, condições climáticas, vestimentas necessárias, equipamentos e cansaço. A partir de toda essa contextualização e preparação, a prática do montanhismo pôde ser desenvolvida de fato.

Após nosso tradicional alongamento e informações para monitoramento cardíaco e Escala Modificada de Borg, caminhamos por 5 horas e 45 minutos contando os tempos de paradas, para lanches, almoço e aferimentos de frequência cardíaca e escala modificada de Borg. Saímos de cerca de $1.100 \mathrm{~m}$ de altitude na portaria do PARNASO Petrópolis até os $2.245 \mathrm{~m}$ dos Castelos do Açú. O primeiro pernoite aconteceu no Abrigo de Montanha do Açú, onde foi possível acomodar a equipe entre bivaque, beliche e camping.

O segundo dia de caminhada foi até a Pedra do Sino $(2.275 \mathrm{~m})$, muitas subidas e descidas que exigiram bastante de toda a equipe, passando por trechos técnicos que demandaram atenção maior, como o Elevador (Figura 2), o Mergulho e o Cavalinho (Figura 2) (GARCIA NETO, 2008). O pernoite ocorreu no Abrigo 4, também conhecido como abrigo da Pedra do Sino, na área de camping. O terceiro e último dia foi de descida por cerca de $11 \mathrm{~km}$ até a sede do PARNASO em Teresópolis, concluindo a travessia com êxito e acúmulo de muitos aspectos positivos de autoconhecimento entre os participantes, e também de um maior conhecimento sobre as características ambientais do território percorrido.

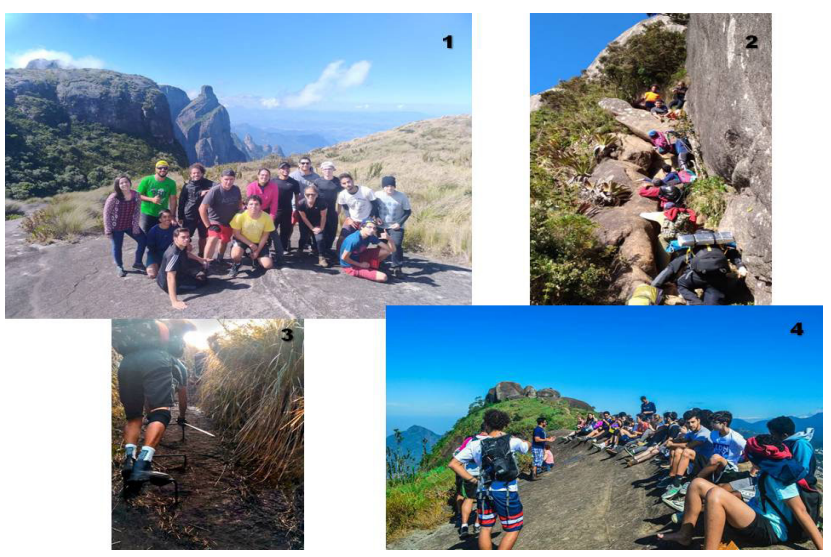

Figura 2. 1. Travessia Petrópolis-Teresópolis; 2. Trecho técnico conhecido como "Cavalinho"; 3. Trecho técnico conhecido como "Elevador"; Morro Meu Castelo (Arquivo pessoal doa autor).
7 - Trilha do Caminho do Ouro - novembro/2018: essa trilha, que possui importante contexto histórico associado, foi aberta no ano de 1723, representando um trecho da Estrada Real que deu origem à Petrópolis, conhecida como Atalho do Proença. Hoje a trilha liga os municípios Magé e Petrópolis, com distância aproximada de $5 \mathrm{~km}$ e classificada como semi-pesada (GARCIA NETO, 2008). O trecho foi percorrido em 5 horas de caminhada, nos acompanhou um condutor de visitantes local, tornando a experiência ainda mais significativa no contexto de uma atividade de turismo de base comunitária. O relevo local e toda a contextualização histórica nos fez pensar no combate ao sedentarismo, discutindo um caminho construído por escravos em meio à mata e hábitos de vida de vida atuais.

Como afirma Santos (2013), o esporte de aventura, que aqui chamamos de práticas corporais de aventura (BRASIL, 2018), é uma atividade que envolve riscos controlados, onde incerteza e contato com a natureza trazem benefícios ao corpo e a mente (LI et al., 2011; BRUHNS, 2009). Estes benefícios melhoram a coordenação motora, força, concentração, atenção, raciocínio, aspectos que estão ligados diretamente ao nosso cotidiano, fazendo desta prática com caráter lúdico e educacional uma linguagem de promoção do autoconhecimento, do desenvolvimento de relações interpessoais, melhorando autoestima, contemplando o caráter interdisciplinar e pedagógico proposto.

Em nosso relato de experiência, ao aferirem a frequência cardíaca e controlarem seu cansaço, colocamos em prática de maneira prazerosa através do montanhismo aulas com a temática de saúde. Os alunos acabam por entender que a prática regular de uma atividade física pode beneficiar um melhor rendimento em atividades como as que acabaram de realizar, o que corrobora com o discurso de Farinatti e Ferreira (2006), onde o caráter multifatorial da saúde transcorre em práticas que possam ajudar a desenvolver um ser humano mais crítico e consciente do ambiente que os cerca. A promoção da saúde perpassa um autoconhecimento e reconhecimento de seus limites e dos que se encontram a sua volta, aspecto evidente nas caminhadas em trilhas.

Promovendo a atividade de montanhismo observamos a questão do imaginário (COSTA, 2000; BRUHNS, 2009), em que, alguns alunos tinham o sonho de realizar tais atividades; sonhos estes, que para as autoras citadas acima, se confundem com os interesses que a mídia pode influenciar, mostrando histórias que atraem pela sedução.

Ouvimos relatos de "sempre quis fazer, mas, não tinha ninguém para me acompanhar". Ao conseguir realizar a trilha, a caminhada ou a travessia, surge o sentimento de conquista, associado a um maior conhecimento sobre seu próprio corpo, além de instigar a curiosidade e o conhecimento sobre o ambiente percorrido. Corroborando o que Piovani (2013) de colaboração das atividades de aventura para desenvolvimento de um indivíduo mais consciente as suas situações de vida, trabalhando a autonomia dos estudantes.

Concordamos com a visão desenvolvida por Pimentel (2006, p. 65) que, ao estudar a trilha do Índio e a volta de Apucarana, apontam duas lógicas associadas às atividades na natureza, uma ligada a "experimentar desafios superiores aos enfrentados no cotidiano, visando aumentar o limiar de tolerância ao esforço físico", e outra "a compensação de aspectos indesejáveis do cotidiano, causadores de baixos níveis de qualidade de vida". Embora as práticas corporais de aventura venham se intensificado a cada ano, foi possível observar no imaginário dos participantes as questões relacionadas pelo autor.

$\mathrm{Na}$ lógica do projeto se constrói a cada atividade de ida a campo uma conexão com a natureza, as atividades de maior tempo de duração, a travessia Cobiçado-Ventania e a traves- 
sia Petrópolis-Teresópolis, nos mostraram efetivamente um aumento da consciência por parte dos alunos da necessidade de preservação dos recursos naturais. A alternativa de lazer diferente das praticadas nos grandes centros urbanos traz uma maior aproximação de formas simples de vida na contrapartida complexidade da vida moderna nas cidades, se buscando alcançar uma melhor qualidade de vida, traduzida em maior interação com a natureza (DIAS, 2008).

Os alunos participantes e os selecionados para as atividades de uma forma geral, foram motivados a aprender no espaço de ambiente natural, de forma prática e interdisciplinar, tanto as questões relativas à educação física quanto geografia, onde destacamos aqui os elementos dos ecossistemas presentes por meio da Interpretação Ambiental, onde para Tilden (1977), é uma atividade que traz significância e inter-relações por meio do contato direto com áreas naturais ao invés de simplesmente fazer esta comunicação de forma literária.

Além disso, Hanai e Netto (2006, p. 211) narram o fato em que visitas estruturadas e com roteiros interpretativos, não só promovem a conscientização ambiental, como enriquecem a experiência de visitação na natureza, satisfazendo as expectativas dos visitantes e auxiliando na valorização dos patrimônios naturais e culturais existentes.

\section{CONCLUSÃO}

O montanhismo, como prática corporal de aventura nas atividades aqui descritas, além de representarem práticas de educação ambiental, destacou as relações entre sociedade e natureza, desenvolvendo nos estudantes o paradigma ecológico atual, ligado a conhecer o meio ambiente, ter o contato, para desta forma, aprender a respeitá-lo.

As atividades aqui apresentadas não têm a intenção de ser modelo de aplicação e sim um relato de nossas experiências e vivências no processo educacional interdisciplinar. O desenvolvimento do projeto, pode ser acompanhado em suas contas nas redes sociais - Facebook $^{\circledR}$ e Instagram $^{\circledR}$, demonstrando o potencial existente em atividades desenvolvidas em áreas naturais, principalmente em trilhas, onde a interpretação ambiental pode ser estimulada a partir de um maior contato com a natureza.

Desta forma a educação física escolar procura resignificar conteúdos e processos de ensino-aprendizagem de forma interdisciplinar a partir de aspectos que influenciam os participantes em termos pessoais, escolares, físicos e também emocionais. Sugerimos o debate com novas pesquisas, questionando ou interagindo com os dados aqui apresentados.

\section{REFERÊNCIAS}

ALVES-MAZZOTTI, A. J.; GEWANDSZNAJDER, F. O método nas ciências naturais e sociais. 2. ed. São Paulo: Thompson, 2002.

BRASIL. Ministério da Educação. Base Nacional Comum Curricular. Brasília: MEC, 2018. Disponível em: <http://basenacionalcomum.mec.gov. br/>. Acessado em: 10 de dezembro de 2018.

BRUHNS, H. T. A busca pela natureza: turismo de aventura. Barueri, SP: Manole, 2009.

CARVALHO, I. C. de M. Educação ambiental: a formação do sujeito ecológico. São Paulo: Cortez, 2008.

CASTRO J. R.; COUTINHO, B. H.; FREITAS, L. E. Gestão da biodiversidade e áreas protegidas. In GUERRA, A. J. T.; COELHO, M. C. N. (Orgs.). Unidades de conservação: abordagens e características geográficas. Rio de Janeiro: Bertrand Brasil, 2009. p. 25-65.

CAVAllazZI, T. G. L.; CAVAllazZI, R. S.; CAVAlCANTE, T. M. C.;
BETTENCOURT, A. N. C.; DICCINI, S. Avaliação do uso da escala modificada de Borg na crise asmática. Acta Paulista de Enfermagem, São Paulo, v. 18, n. 1, p. 39-45, 2005.

COSTA, V. L. de M. Esportes de aventura e risco na montanha: um mergulho no imaginário. Barueri: Manole, 2000.

CRUZ NETO, O. O trabalho de campo como descoberta e criação. In: DESLANDES, S. F.; CRUZ NETO, O.; MINAYO, M. C. de S. (Org.). Pesquisa social: teoria, método e criatividade. Petrópolis: Vozes, 2002. p. 51-66.

DIAS, R. Turismo sustentável e meio ambiente. São Paulo: Atlas, 2008.

DIEGUES, A. C. 0 mito moderno da natureza intocada. São Paulo: HUCITEC, 1996.

FARINATTI, P. de T. V.; FERREIRA, M. S. Saúde, promoção da saúde e educação física: conceitos, princípios e aplicações. Rio de Janeiro: EdUERJ, 2006.

FLICK, U. Uma introdução à pesquisa qualitativa. 2. ed. Porto Alegre: Bookman, 2004.

GARCIA NETO, W. Guia de trilhas de Petrópolis. Petrópolis, 2008.

GIL, A. C. Métodos e técnicas de pesquisa social. 4. ed. São Paulo: Atlas, 1995.

GOMES, R. A análise de dados em pesquisa qualitativa. In: DESLANDES, S. F.; CRUZ NETO, O.; MINAYO, M. C. de S. (Org.). Pesquisa social: teoria, método e criatividade. Petrópolis: Vozes, 2002. p. 67-80.

HANAI, F. Y.; SILVA NETTO, J. P. Instalações ecoturísticas em espaços naturais de visitação: meios para propiciar a percepção e a interpretação ambientais. OLAM Ciência \& Tecnologia, Rio Claro, v. 6, n. 2, p. 200 -23, dez. 2006.

ICMBIO. Instituto Chico Mendes de Conservação da Biodiversidade. Visitação em parques nacionais bate novo recorde em 2018. Disponível em: <http://www.icmbio.gov.br/portal/ultimas-noticias/20-geral/10216visitacao-em-parques-nacionais-bate-novo-recorde-em-2018>. Acessado em: 15 de outubro de 2019.

ICMBIO/PARNASO. Instituto Chico Mendes de Conservação da Biodiversidade/Parque Nacional da Serra dos Órgãos. Caminhos da Serra do Mar. Disponível em: <http://www.icmbio.gov.br/parnaserradosorgaos/ destaques/167-caminhos-da-serra-do-mar.html.>. Acessado em: 15 de agosto de 2019.

LI, Q.; OTSUKA, T.; KOBAYASHI, M.; WAKAYAMA, Y.; ...; KAGAWA, T. Acute effects of walking in forest environments on cardiovascular and metabolic parameters. European Journal of Applied Physiology, Tóquio, v. 111, n. 11, p. 2845-53, 2011.

MENEZES, P. C. O aprendizado brasileiro das trilhas de longo curso no mundo. (O) eco. 2017. Disponível em <http://www.oeco.org.br/colunas/ pedro-da-cunha-e-menezes/o-aprendizado-brasileiro-das-trilhas-delongo-curso-no-mundo/>. Acessado em: 15 de novembro de 2017.

PEREIRA, D. W. Escalada. São Paulo: Odysseus, 2007.

PIMENTEL, G. G. de A. Aventuras de lazer na natureza: o que buscar nelas? In: MARINHO, A.; BRUHNS, H. T. (Org.) Viagens, lazer e esporte: o espaço da natureza. Barueri: Manole, 2006. p. 43-73.

PIOVANI, V. G. S. Atividades de aventura: prática para um tempo livre para o consumo ou para um tempo livre mais humano? Caderno de Educação Física e Esporte, Marechal Cândido Rondon, v. 11, n. 2, p. 61-67, 2013.

PORRETTI, M. F. Contribuições dos docentes de educação física das escolas municipais de Petrópolis sobre uma reflexão curricular para uma sociedade sustentável. 2011. 117f. Dissertação (Mestrado em Ciências da atividade física) - Universidade Salgado de Oliveira, Niterói, 2011.

SANTOS, G. C. dos. Professores de Educação Física frente ao desafio dos esportes de aventura. In: PEREIRA, D. W. (Org.). Atividades de aventura: em busca do conhecimento. Várzea Paulista: Fontoura, 2013. p. 67-80.

THOMAS, J. R.; NELSON, J. K.; SILVERMAN, S. J. Métodos de pesquisa em atividade física. 6. ed. Porto Alegre: Artmed, 2012. 
TILDEN, F. Interpreting our heritage. North Carolina: The University of North Carolina Press, 1977.

\section{AGRADECIMENTOS}

Agradecemos aos colaboradores do projeto de extensão

CEFET/RJ, Campus Petrópolis, os Professores Marcelo Soares Salomão e

João Vinicius Correa Thompson, e aos alunos Bolsistas do projeto

durante o ano de 2018, Luana Pitzer e Lucas Duarte Chaves.

Agradecemos também a todos que participaram das atividades

realizadas pelas atividades do projeto.

\section{CONFLITO DE INTERESSE}

Os autores do estudo declaram não haver conflito de interesses.

\section{FINANCIAMENTO}

Este estudo não contou com apoio financeiro.

\section{ORCID E E-MAIL DOS AUTORES}

Marcelo Faria Porretti (Autor Correspondente)

ORCID: 0000-0002-1576-1633.

E-mail: marceloporretti@gmail.com

Fernando Amaro Pessoa

ORCID: 0000-0003-4562-4274.

E-mail: fap_rj@hotmail.com

Monique Ribeiro de Assis

ORCID: 0000-0002-2747-2601.

E-mail: monique_assis@uol.com.br 